Artigo: Bens básicos, moralidade e dignidade da pessoa humana: fundamentos da teoria da lei natural de Tomás de Aquino

\title{
BENS BÁSICOS, MORALIDADE E DIGNIDADE DA PESSOA HUMANA: FUNDAMENTOS DA TEORIA DA LEI NATURAL DE TOMÁS DE AQUINO
}

\author{
BASIC GOODS, MORALITY AND THE DIGNITY OF THE HUMAN PERSON: FOUNDATIONS OF \\ THOMAS AQUINAS'S NATURAL LAW THEORY
}

\author{
Mário da Silva Ribeiro* \\ Victor Sales Pinheiro**
}

\section{RESUMO}

Neste artigo constam as noções elementares da teoria da lei natural proposta por Tomás de Aquino. Especificamente, analisa-se segundo o método explicativo-compreensivo: 1. o que são bens básicos; 2. o que são princípios práticos básicos; 3. qual o fundamento da moralidade; 4. como absolutos morais podem ser conhecidos; e 5. qual o vínculo entre todos esses pontos e a dignidade humana. Para tanto, são aprofundadas as considerações originariamente dispostas no tópico 3.5 da Dissertação de Mestrado em Direito intitulada Aborto: fundamentos biológico-filosóficos da sua (anti)juridicidade (RIBEIRO, 2019), a qual utiliza como referencial interpretativo do jusnaturalismo tomista os trabalhos desenvolvidos no âmbito da Nova Escola da Lei Natural, sem que isso implique, porém, a reprodução exata das ideias de cada um dos autores que a compõem. A justificativa deste artigo remonta ao necessário avanço de estudos atentos a benefícios autoevidentes que dizem respeito à realização pessoal dos seres humanos. E mais, devido às lacunas da literatura nacional filosófico-jurídica, tal justificativa remonta também à urgência de se proporcionar aos estudiosos uma visão holística das lições do principal expoente da tradição da lei natural, uma espécie de itinerário auxiliar para a informação e formação intelectual.

PALAVRAS-CHAVE: Aquino. Lei Natural. Bens Básicos. Moralidade. Dignidade Humana.

\section{ABSTRACT}

This article contains the foundations of the natural law theory proposed by Thomas Aquinas. Specifically, it analyzes according to the explanatory-comprehensive method: 1 . What are basic goods; 2 . What are basic practical principles; 3 . What is the foundation of morality; 4 . How moral absolutes can be known; and 5. What is the link between all these points and human dignity. To this end, it deepens the considerations originally set out in topic 3.5 of the Master's Thesis in Law entitled Abortion: biological-philosophical foundations of its (anti)juridicity (RIBEIRO, 2019), which uses as an interpretative reference the works developed by the New School of Natural Law, without this implying, however, the exact reproduction of the ideas of each of the authors who compose it. The justification of this article goes back to the necessary advance of studies attentive to self-evident benefits that concern the personal fulfillment of human beings. But not just that. Due to the gaps in national literature at the juridical-philosophical level, such justification also goes back to the urgency of providing scholars with a holistic view of the lessons of the main exponent of the tradition of natural law, a kind of auxiliary itinerary for information and intellectual training. KEYWORDS: Aquinas. Natural law. Basic goods. Morality. Human dignity.

\footnotetext{
* Doutorando e Mestre em Direito, com ênfase em Filosofia, pela Universidade Federal do Pará (UFPA). Email: msribeiro1410@gmail.com.

** Doutor em Filosofia pela Universidade do Estado do Rio de Janeiro (UERJ). Mestre em Filosofia pela Pontifícia Universidade Católica do Rio de Janeiro (PUC-RIO). Email: vvspinheiro@yahoo.com.br.
} 


\section{INTRODUÇÃO}

A teoria da lei natural proposta por Tomás de Aquino não decorre de uma intuição juvenil ou de uma inspiração intelectual sem precursores. É tão somente após assimilar perspectivas diversas, com destaque para as advindas de Aristóteles, dos estoicos, dos juristas romanos, das Escrituras e de Agostinho de Hipona, que Aquino elabora um pensamento bem ordenado sobre a temática jusnaturalista. Em outras palavras, embora Tomás de Aquino publique reflexões relacionadas à conduta humana já na sua primeira grande obra Comentário às sentenças de Pedro Lombardo —, é na Suma teológica que ele, anos mais tarde, expõe uma concepção sistematicamente organizada da lei natural.

$\mathrm{Na}$ tentativa de melhor esclarecer tal concepção, no presente artigo constam as noções elementares que orientam o raciocínio de Aquino nesse campo. Especificamente, analisa-se segundo o método explicativo-compreensivo: 1. o que são bens básicos; 2. o que são princípios práticos básicos; 3. qual o fundamento da moralidade; 4. como absolutos morais podem ser conhecidos; e 5. qual o vínculo entre todos esses pontos e a dignidade humana. Para tanto, são aprofundadas as considerações originariamente dispostas no tópico 3.5 da Dissertação de Mestrado em Direito intitulada Aborto: fundamentos biológico-filosóficos da sua (anti)juridicidade (RIBEIRO, 2019), a qual utiliza como referencial interpretativo do jusnaturalismo tomista os trabalhos desenvolvidos no âmbito da Nova Escola da Lei Natural, sem que isso implique, porém, a reprodução exata das ideias de cada um dos autores que a compõem ${ }^{1}$.

As linhas a seguir, portanto, reúnem anotações propedêuticas, inobstante técnicas. Sua justificativa remonta ao necessário avanço de estudos atentos a benefícios autoevidentes que dizem respeito à realização pessoal dos seres humanos. E mais, devido às lacunas da literatura nacional filosófico-jurídica, tal justificativa remonta também à urgência de se proporcionar aos estudiosos uma visão holística das lições do principal expoente da tradição da lei natural, uma espécie de itinerário auxiliar para a informação e formação intelectual.

Assim, este artigo se divide da seguinte maneira:

Na primeira seção, consta uma apresentação dos chamados bens básicos ou intrínsecos identificados por Tomás de Aquino. Em seguida, nas seções dois e três, destaca-se o elo

\footnotetext{
${ }^{1}$ A Nova Escola da Lei Natural tem origem na década de 1960. Entre os seus principais colaboradores estão Germain Grisez, Joseph Boyle, Olaf Tollefsen, John Finnis, Robert P. George, Patrick Lee, Gerard Bradley, Willian E. May, Peter Ryan, Christian Brugger e Christopher Tollefsen.
} 
Artigo: Bens básicos, moralidade e dignidade da pessoa humana: fundamentos da teoria da lei natural de Tomás de Aquino

desses bens com o que se pode denominar de princípio formal da razão prática, princípios práticos básicos e princípio supremo da moralidade, os quais constituem a primeira ordem de preceitos da lei natural tomista. Na quarta seção, sem a pretensão de se desconsiderar a relevância dos últimos preceitos da teoria jusnaturalista de Aquino (os preceitos de terceira ordem que apenas os sábios conhecem por si), há um cuidado particular com o processo dedutivo de certos deveres e direitos morais absolutos, normas que o próprio Aquino aponta como preceitos de segunda ordem cuja observação garante o mínimo de justiça em todas as comunidades, possibilitando-lhes a experiência do bem comum. Na seção cinco, acrescenta-se que a dignidade da pessoa humana condiciona a lei natural tomista. E, por fim, a título conclusivo, sintetiza-se tudo o que está dito nas seções precedentes.

\section{BENS BÁSICOS}

Entre os fundamentos assumidos por Tomás de Aquino para formular a sua teoria da lei natural está a convicção aristotélica de que o ser humano, pelo uso da razão, sempre age em vista de um ou mais bens; fins dos mais variados tipos que existem por conta das mais variadas ocupações. Examinada a conduta humana, pensa Aquino, verifica-se ao menos algum objetivo, alguma intencionalidade previamente deliberada. Um médico almeja a saúde; um professor, o conhecimento; um estrategista visa à vitória; e um assaltante, o assalto. $\mathrm{O}$ bem ou o fim segue o ato, de maneira a inexistir ação ou omissão alheia a propósitos. (AQUINO, 2003d, 2003e).

Aquino destaca, entretanto, que certos bens são desejáveis em si mesmos. São bens últimos ou primeiros (2003d), também designados contemporaneamente de bens básicos, fundamentais ou intrínsecos (FINNIS, 1998; GEORGE, 2001; LEE, 2009). Tais bens são aqueles fins constitutivos dos atos humanos que, uma vez intelectualmente apreendidos, sequer demandam um processo posterior de explanação ou demonstração do seu benefício para o ser humano. Os bens básicos, pode-se dizer, mesmo quando compreendidos em termos gerais, são propósitos atraentes ao homem em virtude do benefício evidente que representam para a sua realização pessoal (AQUINO, 2003d).

Mas quantos e quais são esses bens? Apesar de negligenciar esclarecimentos ordenados em uma lista, Aquino certamente identifica, no mínimo, seis bens básicos: vida, matrimônio, conhecimento, sociabilidade, religião e razoabilidade prática (FINNIS, 1998). De fato, sendo a vida o contrário da morte, nada mais é necessário para a assimilação do seu 
benefício intrínseco, manifestado na saúde e na integridade física (AQUINO, 2003c, 2003d, 2003f, 2003g). E achando-se o matrimônio fundado na complementaridade do casal, bem como na criação de seus filhos e atividades afins, também não lhe é estranha a obviedade do proveito (AQUINO, 2003d, 2003g). É certo também que, por ser o conhecimento antitético à ignorância, não se pode, do ponto de vista lógico, questionar a sua vantagem (AQUINO, 2003c, 2003d, 2003f); tal como é vantagem segura a harmonia entre os seres humanos, fundamento da sociabilidade (AQUINO, 2003c, 2003d,2003e, 2003g). Parece ainda que, dada a perfeição absoluta de Deus, pouco ou nenhum esforço é necessário para se apreender o benefício da religião enquanto finalidade ou propósito de procurá-Lo e encontrá-Lo (AQUINO, 2003a); ausência de esforço, aliás, que se repete quando se compreende que a razoabilidade prática não é senão aquele fim que orienta o ser humano a não contrariar nenhum dos bens básicos acima mencionados (AQUINO 2003d, 2003e).

No fundo, o que Aquino defende é que esses seis bens (marcados pela capacidade de dispensar justificativas de atualização) jamais constituíram ou constituirão um malefício para os membros da espécie humana. Uma analogia pode elucidar o que se diz aqui².

É sabido, por exemplo, que as moléculas de água compõem a maior parte do corpo humano. Sem elas as funções vitais seriam impossíveis. Isso significa que a água em si é um benefício para a humanidade, e note-se: quer dizer também que, enquanto tal, ela sempre o é. Tão somente quando ingerida em excesso ou contaminada pode haver um prejuízo orgânico, porém a causa do prejuízo - em nenhuma hipótese - é a água propriamente, e sim o excesso ou a contaminação que a acompanham.

Ora, não é diferente com os bens básicos. Eles nunca são em si mesmos maléficos aos seres humanos. Se uma pessoa almeja morrer ou considera a sua existência uma miséria, não é porque a vida é um mal; a doença, a dor e a pobreza são as coisas ruins. Se uma sociedade perde a paz e os seus membros já não vivem em harmonia, não é a sociabilidade o malefício em questão, os atos que a contrariam que o são. Assim se dá com qualquer bem básico.

Daí a possibilidade de se assegurar a presença destes desde o princípio da história humana. Todas as comunidades estimaram e estimam a vida, elevando a conservação da existência ao status de importante diretriz social; em todas, sempre constituiu preocupação primeira as relações matrimoniais, e nenhuma desprezou a passagem do desconhecido para o conhecido, como se a verdade fosse ilusória. Em cada comunidade, a paz social e a livre relação com um Ser Supremo foram e continuam a ser motivo de inquietude — jamais lhes

\footnotetext{
${ }^{2}$ Deve-se essa analogia às lições de Gómez-Lobo (2002).
} 
Artigo: Bens básicos, moralidade e dignidade da pessoa humana: fundamentos da teoria da lei natural de Tomás de Aquino

pareceu desinteressante os limites do agir, as figuras autoritativas e o rol de direitos e deveres. Todas as nações assimilam continuamente os bens básicos; todas as gerações, há muito, já os entenderam. É que aquilo que é evidentemente próprio à realização pessoal o homem, pela razoabilidade prática, nunca esquece.

\section{PRINCÍPIOS PRÁTICOS BÁSICOS}

Não se pense disso tudo que os bens - básicos ou não - existem em abstrato, desconexos das experiências históricas particulares dos seres humanos, como se estivessem livres e dispersos no mundo. Eles existem, adverte Aquino (2003d), a partir de princípios práticos; elaborações mentais que estabelecem um caminho a ser seguido para a consecução de um ou mais bens. Exemplos não faltam. É assim quando se assimila que o dinheiro é relevante de se ter, quando se toca um instrumento musical, quando se leva um cão para passear, e mesmo quando se toma um copo d'água. Em todos os momentos em que as pessoas se propõem a fazer ou a não fazer algo, elas deliberam e escolhem os atos que melhor satisfazem a este ou àquele fim, constituindo mentalmente princípios práticos sujeitos a infinitas configurações.

Aquino sabe dessa infinitude, mas assegura que os princípios práticos podem ser formalmente reduzidos a um só, aquele segundo o qual "o bem é para ser feito e perseguido, e o mal é para ser evitado" (1981, ST $T^{3}$, I-II, q. 94 a.2c, tradução nossa), entendendo-se por mal tudo aquilo que é contrário ao bem visado (FINNIS, 1998; GRISEZ, 1965). Quem estiver direcionado a alguma finalidade, sempre estará adstrito a essa formulação. Seja jurista ou torturador, escritor ou pedinte, todo ser humano, almejando um bem, procura instanciá-lo nos moldes desse primeiro princípio prático. Trata-se de uma formulação paradigmática autoevidente (AQUINO, 2003d).

Ressalve-se, contudo, que a expressão tomista é para ser não consiste em mero capricho linguístico. Como dito, os princípios práticos que instanciam os bens estabelecem uma direção, um caminho a ser seguido; eles nunca indicam o que é ou o que será, muito menos ditam um comando ou uma ordem. Não à toa pode-se afirmar que eles são pré-morais; jamais se expressam como normas de conduta sobre o certo e o errado, sobre o bom e o mau (FINNIS, 1998; GRISEZ, 1965; TOLLEFSEN, 2017). Isso vale, inclusive, para o que se pode

\footnotetext{
${ }^{3}$ Nas chamadas das citações, identificaremos a obra Suma teológica com ST.
} 
denominar de princípios práticos básicos, os quais, distinguindo-se dos demais princípios práticos por instanciarem bens básicos ou primeiros, asseguram que:

1. A vida é para ser feita e perseguida, e tudo o que lhe for contrário é para ser evitado.

2. O matrimônio é para ser feito e perseguido, e tudo o que lhe for contrário é para ser evitado.

3. O conhecimento é para ser feito e perseguido, e tudo o que lhe for contrário é para ser evitado.

4. A sociabilidade é para ser feita e perseguida, e tudo o que lhe for contrário é para ser evitado.

5. A religião é para ser feita e perseguida, e tudo o que lhe for contrário é para ser evitado. E, por fim,

6. A razoabilidade prática é para ser feita e perseguida, e tudo o que lhe for contrário é para ser evitado.

Aqui, três observações são necessárias. A primeira é que a lista acima não é hierárquica. "Como razões últimas para as ações, os bens humanos [básicos] e as suas instanciações são irredutíveis uns aos outros ou a qualquer outra categoria mais fundamental." (GEORGE, 2001, p. 50, tradução nossa). Aquino, parece, sustenta essa posição ou assim indica entender quando reconhece que "a ninguém é lícito matar-se por temor de consentir no pecado" (2003f, ST, II-II, q.64 a.5 ad3) e quando enuncia que "não é lícito matar a mãe para batizar a criança" (2003h, ST, III, q.68 a.11 ad3) - duas situações em que o bem básico da vida seria contrariado em nome do bem básico da religião, o qual costuma ser designado por muitos como o mais proeminente dos bens para o aquinate.

A segunda observação, por sua vez - esta expressamente desenhada por Aquino (2003d) - , consiste em dizer que os princípios práticos básicos são per se nota omnibus ou autoevidentes: eles não são conclusões advindas de proposições ou premissas anteriores. Ao instanciarem benefícios desejáveis em si mesmos, isto é, que não derivam nem são intrinsecamente meios para outros benefícios, os princípios práticos básicos acabam por ser óbvios, proposições incontestáveis.

A terceira e última observação, enfim, é que a autoevidência desses princípios leva Aquino a alocá-los no que entende como a primeira ordem de preceitos da lei natural, uma 
Artigo: Bens básicos, moralidade e dignidade da pessoa humana: fundamentos da teoria da lei natural de Tomás de Aquino

ordem invariável, acessível por todos os seres humanos. Ele diz, por exemplo, na "Prima secundae partis" da sua Suma teológica, q.94 a.6c, que:

\begin{abstract}
Pertencem à lei natural, primeiro, certos preceitos mais gerais que são conhecidos por todos; e, segundo, certos preceitos secundários e mais detalhados, que são, por assim dizer, conclusões que seguem de perto os primeiros princípios. Quanto a esses princípios gerais, a lei natural de nenhum modo pode ser abolida do coração dos homens de forma universal. (1981, ST, I-II, q.94 a.6c, tradução e grifo nossos).
\end{abstract}

Mais adiante, na q. 100 a.3c da mesma "Prima secundae partis", após explicitar que o decálogo pertence à lei natural, Aquino escreve:

[...] dois tipos de preceitos são desconsiderados entre os preceitos do decálogo: princípios primeiros comuns, pois estes não precisam de promulgação depois de escritos na razão natural pela qual são autoevidentes; [...] e aqueles que a reflexão diligente dos sábios revela estar de acordo com a razão [...] (1981, ST, I-II, q. 100 a.3c, tradução e grifo nossos).

Como se vê, o jusnaturalismo tomista repousa em uma estrutura bem definida de três ordens ou classes preceituais, cujo alicerce principiológico não é arbitrário, nem resulta automaticamente dos instintos inerentes a cada pessoa; pelo contrário, a primeira ordem de preceitos da lei natural comporta aquilo que a razão assimila ser autoevidente no plano da conduta humana, um gatilho para a ação ou omissão baseado na apreensão intelectual de que o bem é para ser feito e perseguido, e tudo o que lhe for contrário é para ser evitado.

Cabe dizer, a propósito, diferentemente do que poderia parecer, que nenhuma das duas últimas observações declara certo inatismo dos bens básicos e dos seus respectivos princípios práticos. Aquino pensa que uma proposição evidente por si só é apenas conhecida quando os seus termos são compreendidos, e essa compreensão não pode ser obtida sem experiência (AQUINO, 2003a). Por palavras distintas, para Aquino, o conhecimento dos bens básicos e dos princípios correspondentes perpassa pelo desenrolar da razão na experiência social; um desenrolar que, já em dado momento da infância, toma os fatos conservados na memória e, apoiado neles, compreende que certos bens são realidades a serem feitas e perseguidas (AQUINO, 2003d).

Tal relação entre experiência, razão e bens pode assim ser ilustrada. Quando criança, o ser humano experimenta a vida como o oposto da morte em várias situações: falecimento de entes queridos, meios de entretenimento, grandes desastres etc. Experimentando tudo isso o ser humano gosta, ou sente empatia pelo viver e, por outro lado, não gosta, ou não sente 
empatia, pela morte. Ele se encontra emocionalmente envolvido, mas ainda não tem a percepção prática do que está em questão. Em algum momento, entretanto, mesmo quando criança, o ser humano vai adiante e entende que viver é uma condição que vale a pena perseguir, e que morrer é uma condição para ser evitada.

Outro exemplo é bem dado por Robert P. George (2017, p. 58, tradução e grifo nossos):

\begin{abstract}
Em nossa experiência de admiração e curiosidade, de levantar questões e elaborar estratégias para obter respostas corretas, de executar essas estratégias conduzindo linhas de investigação, [...] apreendemos [...] o ponto inteligível da busca da verdade e o encontramos. Entendemos que o conhecimento, embora possa ter um tremendo valor instrumental, também é intrinsecamente valioso. Estar atento, informado, pensativo, lúcido, cuidadoso, crítico e judicioso no pensamento e no julgamento $e ́$ para ser inerentemente enriquecido em uma dimensão fundamental da vida humana. Assim, julgamos razoavelmente a atividade de saber como sendo um bem humano intrínseco (ou básico) - um aspecto constitutivo e irredutível de nosso florescimento como seres humanos.
\end{abstract}

É claro que esse entendimento espontâneo daquilo que é intrinsecamente benéfico chega a cada um conforme as balizas da experiência própria, algo que a teoria exposta não ignora. Toda pessoa humana, reconhece Aquino, percorre um trajeto existencial particular e traz consigo características acidentais específicas (sexo, idade, cor, religião, renda etc.), fazendo-se inevitável notar que o homem, em ato, jamais será a atualidade completa das potências do seu ser (AQUINO, 2003b).

Alguém pode ter sérias dificuldades para apreender este ou aquele bem básico, ou mesmo pode ser funcionalmente incapaz de reproduzir tal processo de conhecimento. Práticas, vale lembrar, que alimentam a inferiorização da mulher perante o homem, a morte premeditada de inocentes, as pequenas ou grandes mentiras, a intolerância religiosa, o racismo nas suas incontáveis variações, entre outros exemplos, são, certamente, manifestações prejudiciais ao alcance dos bens básicos; da mesma maneira que são adversas as doenças, síndromes e transtornos que acometem a capacidade intelectual do homem.

A noção, portanto, de que o ser humano inexiste despido de atributos contingentes está inclusa na perspectiva tomista de que os primeiros preceitos da lei natural são conhecidos nos graus sucessivos da experiência, a começar pela infância. E isto confere uma nota peculiar (rigorosa) ao jusnaturalismo de Aquino: nele o homem é muito mais que um modelo estático ou um paradigma ideal; é um ser racional circunstancialmente circunscrito. 
Artigo: Bens básicos, moralidade e dignidade da pessoa humana: fundamentos da teoria da lei natural de Tomás de Aquino

\section{PRINCÍPIO SUPREMO DA MORALIDADE}

Assente o que são bens básicos e princípios práticos básicos, deve-se dizer que o processo de conhecimento que os envolve - chamado por alguns estudiosos de insight prático (FINNIS; GRISEZ; BOYLE, 1987, FINNIS, 1998, LEE, 2009) —, conquanto não seja um processo de imediata regulação moral, constitui o itinerário embrionário da moralidade.

Assim o é porque, em determinado momento da sua vida infante, o ser humano percebe a necessidade de ir além daquilo que sem dúvidas é para ser feito e perseguido. Ele começa a amar intelectualmente com maior profundidade, e como "amar é querer bem a alguém” (AQUINO, 2003c, ST, I-II, q. 26 a.4c), ele compreende que os bens básicos devem ser feitos e perseguidos em prol daqueles que ama. Ao fazer isso, o ser humano não realiza um movimento intelectual cego, uma aposta; realiza a instanciação moral do bem básico da razoabilidade prática nos limites daqueles que lhe parecem ser os genuínos merecedores do seu amor - a princípio, as pessoas mais íntimas.

Com o passar do tempo, cada ser humano amplia os laços sociais, fazendo da experiência do outro uma experiência de autoconstituição. E, caso esteja livre de distorções intelectuais graves (como o racismo, por exemplo), reconhece que os sujeitos do amor - os próximos, os vizinhos, os irmãos - são aqueles que possuem características iguais e similares às suas, são todos aqueles de natureza humana. $\mathrm{O}$ homem, para utilizar expressão aristotélica repetida por Tomás de Aquino (2003b, ST, I, q. 79 a.2c), surge como "uma tábula rasa em que nada está escrito", uma realidade que, estando avessa a desvios de compreensão, percebe que é evidentemente valioso existir em amor para com o seu semelhante, pois pelo amor mútuo instancia-se, como obrigação absoluta, o zelo pelos bens básicos, benefícios intrínsecos.

Se é bem verdade que na criança ocorre, primeiro, a experiência dos outros que a circundam e, em seguida, o chamado contínuo de figuras interpelativas que estendem o círculo de proximidade (MARCEL, 1951), parece não menos verdadeiro que a ausência de equívocos intelectuais severos torna humanamente irrestrita essa mesma extensão. Nesse sentido, a assimilação do próximo como o homem enquanto tal é provável já a nível prático sem que algum exercício especulativo profundo seja necessário. Considerar o outro como um outro eu não é atributo exclusivo das grandes mentes; a estas cabe enfrentar as apaixonadas 
distorções que obscurecem a incontestável avaliação de que toda pessoa humana deve ser amada.

O que se diz aqui é enfatizado por Tomás de Aquino de maneira sintética e elucidativa. Ele entende que o conjunto de princípios práticos básicos apreendidos pela razão é passível de uma redescrição normativa em um único princípio autoevidente, um princípio que é a instanciação ilimitada da razoabilidade prática no plano da moralidade — "amarás teu próximo como a ti mesmo" (AQUINO, 2003d, I-II, q.99 a.1 ad.2). Em palavras mais concretas, o que Aquino quer dizer é que os princípios práticos básicos, em sua totalidade, podem ser moralmente redescritos segundo a prescrição de que os bens básicos devem ser feitos e perseguidos em auxílio de qualquer membro da humanidade, e ninguém deve praticar atos que os contrariem ${ }^{4}$. Aquele que, amando a si, ama também ao seu irmão ou vizinho, moraliza o próprio conjunto de princípios práticos básicos, um conjunto cuja consubstanciação garante a atualização de benefícios em si mesmos desejáveis para todas as comunidades humanas.

Convém ponderar, ainda, que Aquino permite a interpretação de que esse princípio supremo da moralidade é também, em certo sentido, a causa final do ser humano, a sua razão de ser, muito embora importantes autores compreendam distintamente ou não sejam enfáticos a esse respeito. Não se nega, decerto, a conhecida convicção do aquinate de que a causa final humana é realizada perfeitamente pela beatitude, que consiste na intimidade plena com Deus (AQUINO 2003c). Apenas se acrescenta a essa convicção uma outra, mais racional, apontada pelo próprio Tomás de Aquino: a beatitude, que é o telos último das obras humanas, pode ser alcançada imperfeitamente mediante a incessante instanciação moral da razoabilidade prática, isto é, mediante a contínua conduta de amor que resguarda os bens básicos para si e para outrem (AQUINO, 2003c, 2003d). É nesse sentido que se fala aqui na causa final do ser humano.

De fato, sendo o homem um ser racional que vive em comunidade, seria inusitado que a sua causa final destoasse da capacidade moral de se atuar nos termos dos bens básicos e de se desconsiderar tudo que os viola. E como essa capacidade expressa o gosto ou a alegria pelo benefício próprio e alheio, objeto do amor (AQUINO, 2003c), seria igualmente inusitado que a causa final do ser humano não pudesse ser declarada em consonância com o princípio

\footnotetext{
${ }^{4}$ Esta formulação não é, parece, excludente daquela proposta por Finnis, Boyle e Grisez (1987, p. 283, tradução nossa): "O primeiro princípio da moralidade pode, talvez, ser melhor formulado: agindo voluntariamente em busca de bens humanos e evitando o que se opõe a eles, deve-se escolher e, à parte isso, desejar, aquelas e somente aquelas possibilidades cujo querer seja compatível com a realização humana integral."
} 
Artigo: Bens básicos, moralidade e dignidade da pessoa humana: fundamentos da teoria da lei natural de Tomás de Aquino

supremo da moralidade. Ou seja, a razão de ser do homem é a moralidade constante do agir razoável, e agir constantemente de maneira razoável é agir sob as bases do amor universal.

Por aí se nota que a causa final não advém a cada um como se quer. Firmada nos bens básicos, ela é imprescindível para orientar a boa conduta do ser humano. Querer aquilo que não convém, que não é razoável, representa a suma miséria e encoraja a autodestruição, indicando-se certo advertir que "quando a vontade não está submissa à razão é sem moderação toda pertinácia [...] assumida" (HILÁRIO apud AQUINO, 2003c, ST, I-II, q. 19 a. 3c). Não basta ao homem simplesmente ser; ele sempre deve pôr em prática a tendência à vida moral que o habita, impondo razoabilidade às suas múltiplas experiências.

Pode-se dizer, assim, com Aquino, que o princípio do amor ao próximo é teleologicamente comum a todo ser humano e consiste no primeiro absoluto moral a ser promovido. Dele derivam as normas gerais ou específicas que constituem a moralidade. Ele é a raiz da harmonia a ser atingida, e, ao mesmo tempo, a própria harmonia in concreto. É o começo e o fim do universo moral (AQUINO, 2003d).

\section{ABSOLUTOS MORAIS}

Dito isso, novamente algumas observações precisam ser feitas - desta vez, quatro. Primeiro, que os célebres princípios o homem não deve fazer mal a ninguém; o homem deve tratar o seu irmão como gostaria de ser tratado; o homem jamais deve buscar o bem pelo malefício, entre vários semelhantes, são exemplos de normas morais gerais decorrentes do princípio supremo da moralidade, porquanto já estão implicitamente nele contidas (AQUINO, 2003 d). Segundo, que esses comandos principiológicos — por serem autoevidentes, garante Aquino, - ainda pertencem à chamada primeira ordem de preceitos da lei natural, e não à segunda, composta por normas morais específicas igualmente oriundas do princípio supremo da moralidade, porém a partir de deduções (AQUINO, 2003d). Terceiro, que algumas dessas normas deduzidas são absolutas ou invariáveis, enquanto outras, apesar de importantes, não estão cingidas por nenhuma obrigação de respeito integral (AQUINO, 2003d). E a quarta observação, finalmente, é que, para os fins deste artigo, interessa tão somente como surgem os absolutos específicos da moralidade, fazendo-se aqui desnecessário averiguar o surgimento daquelas normas morais suscetíveis à exceção ou daqueles preceitos da lei natural reservados aos sábios, os preceitos que Aquino aloca na terceira ordem (AQUINO, 2003d). 
Importa, pois, indagar de que maneira o ser humano, partindo de um princípio altamente abstrato, pode inferir preceituações que devem condicionar todo o processo histórico-cultural. Aquino destaca que tal operação não requer grande empenho intelectual (AQUINO, 2003d). E assim o diz, indica-se, porque o princípio supremo da moralidade, ao comportar em sua própria estrutura a exigência fundamental de que não se deve contrariar nenhum bem básico, cria condições para os subsequentes processos dedutivos:

1 Primeiro processo dedutivo:

1.1 Os bens básicos devem ser realizados e perseguidos em auxílio de qualquer membro da humanidade, e ninguém deve praticar atos que os contrariem.

1.2 $X$ é um bem básico.

1.3 O bem básico $x$ deve ser realizado e perseguido em auxílio de qualquer membro da humanidade, e ninguém deve praticar atos que o contrariem.

2 Segundo processo dedutivo:

2.1 O bem básico $x$ deve ser realizado e perseguido em auxílio de qualquer membro da humanidade, e ninguém deve praticar atos que o contrariem.

2.2Y é um ato que contraria o bem básico $x$.

2.3 O bem básico $x$ deve ser realizado e perseguido em auxílio de qualquer membro da humanidade, e ninguém deve praticar o ato $y$ que o contraria.

Por conseguinte, reconhecendo-se que matar, adulterar, mentir, roubar, e frustrar a devoção religiosa são exemplos de atos que rigorosamente (ou potencialmente) contrariam bens básicos, pouco esforço é necessário para se apreender ao menos alguns deveres morais absolutos, como: 1. o dever de não matar; 2. o dever de não cometer adultério; 3. o dever de não mentir; 4. o dever de não roubar; e 5. o dever de não impedir a devoção religiosa.

Note-se que, embora esses deveres absolutos sejam requerimentos da razão, eles, tal como os princípios práticos básicos, não são deduzidos de um conhecimento a priori da natureza humana (FINNIS, 1991; MAY, 1989). O espectro permanente da moralidade está longe de ser uma prerrogativa dos experts ou dos sábios; é uma captação simples da razão dirigida ao ato, cabendo ao raciocínio especulativo um papel de menor ênfase. Daí por que a maioria das crianças compreende, em parte, o que jamais deve fazer ou deixar de fazer. Lembre-se, a título ilustrativo, da relação de amor entre pais e filhos. Logo que os filhos atingem a maturidade racional necessária para se assimilar, conjugadamente, o bem básico da vida e o amor pelos pais, eles compreendem que não devem infligir dor a estes, tampouco matá-los. Eles, em que pese o pouco ou quase nulo conhecimento teórico, entendem que 
Artigo: Bens básicos, moralidade e dignidade da pessoa humana: fundamentos da teoria da lei natural de Tomás de Aquino

devem agir para preservar a vida dos seus pais, e não o contrário. De igual modo é com os demais bens básicos.

O mais relevante a ser notado, no entanto, é que os deveres morais absolutos determinam o que, invariavelmente, é de cada um, possibilitando a todos os seres humanos atuar conforme aquilo que é sempre seu - direitos morais absolutos. Não poderia ser diferente. Onde há uma responsabilidade moral imutável, há algo verdadeiramente devido, e aquilo que é verdadeiramente devido não é senão, como diz Aquino (2003f), um direito. Assim, 1. ao dever moral absoluto de não matar corresponde o direito moral absoluto de não ser morto por outrem; 2. ao dever moral absoluto de não cometer adultério corresponde o direito moral absoluto de não ser traído em matrimônio; 3. ao dever moral absoluto de não mentir corresponde o direito moral absoluto de conhecer a realidade dos fatos; 4. ao dever moral absoluto de não roubar corresponde o direito moral absoluto de não ser roubado; e 5. ao dever moral absoluto de não impedir a devoção religiosa corresponde o direito moral absoluto de praticar os atos relativos à fé.

Outros deveres e direitos moralmente absolutos poderiam ser apontados, mas é suficiente observar que o respeito aos absolutos morais garante o mínimo de justiça — "o ato de dar a cada um o que é seu" (AQUINO, 200f, ST, II-II, q. 58, a.11c), e que, mediante a justiça minimamente concretizada, torna-se possível o bem comum ou a causa final humana no seio social: aquele processo constante de amor mútuo pelo qual cada membro da comunidade faz do agir moralmente razoável uma constante existencial (AQUINO, 2003c, 2003d, 2003e, 2003f).

Quer dizer, demonstrada a existência de absolutos morais, é fundamental, para além de um arrolamento completo, que se atente que a consequência inevitável da efetivação destes consiste na consecução (mínima, que seja) da justiça e na fomentação do bem comum. Como não seria assim, se os atos dissonantes aos deveres e direitos moralmente absolutos são em si mesmos maus?

Os absolutos morais constituem a medida de uma existência de amor, uma existência que abarca o arco de relações iniciado com a família e culminado no plano internacional. Pela sua universalidade, eles permitem que o ser humano perceba com maior clareza que a sua titularidade jurídica é natural, não uma concessão social. Tal titularidade se manifesta antes de positivação, quando o ser humano surge para o mundo. Embriões, fetos, recém-nascidos, crianças, adolescentes, adultos e idosos têm deveres e direitos morais. Não só isso. Todos têm 
deveres e direitos morais absolutos a despeito de incapacidades fáticas ou de circunstâncias culturais específicas (AQUINO, 2003a, 2003d).

Por isso não cabe ao legislador de qualquer ordenamento jurídico-positivo fazer o que bem entende, como se inexistisse uma objetividade moral no âmbito das relações humanas. A lei positiva, objeto do seu trabalho, existe para que o bem comum seja atingido (AQUINO, 2003d), fato impossível na hipótese de supressão dos absolutos morais. Sem dúvida, caso o legislador verifique que existe harmonia entre os costumes da comunidade e o bem comum, ele deve fazer da positivação de deveres e direitos uma experiência de concretude temporal e espacial, como ensina Tomás de Aquino (2003d); mas é também incumbência sua - e essa é igualmente uma lição do aquinate — vincular a lei positiva às disposições apreendidas pela razão como moralmente absolutas, o que, se por um lado abranda o alcance da inovação legislativa, por outro garante vigência histórica a um campo incondicional da moral inerente ao bem comum enquanto tal (AQUINO, 2003d).

A lei positiva, então, deve ter aspectos ou elementos mutáveis e imutáveis. Em situações contingentes - a ampla maioria —, faz-se primordial a sua variação de comunidade para comunidade (e, é claro, com a própria comunidade). É o caso daquelas situações relacionadas ao tráfego de veículos, às prioridades em atendimentos diversos, aos fornecimentos gratuitos de medicações específicas, aos documentos necessários para a compra de um imóvel, e assim por diante. Já em relação a certos atos que, independentemente das circunstâncias, são sempre errados por conta da escolha deliberada de violar bens básicos, não cabe nenhuma diversidade substancial no registro legal. Restringir esses atos é antes uma obrigação comum de todos os legisladores em todas as comunidades ${ }^{5}$.

A pluralidade jurídico-positiva propagada por Tomás de Aquino não suprime o fato apontado, e difundido por ele mesmo, de que existem normas morais específicas destinadas a impedir atos humanos absolutamente errados; nem mesmo afasta a sua convicção de que a lei positiva deve estar adstrita à moralidade conducente ao bem comum.

Disso se vê que a lei natural tomista não é intolerante, em sentido diverso ao que um ilustre autor do século XX como John Rawls declara (1971). O que Aquino não tolera é a prática de atos contrários aos deveres e direitos incapazes de acarretar injustiças. Ele, aliás, é

\footnotetext{
${ }^{5}$ Quando o legislador transfere quase que diretamente para a lei positiva certa norma moral constitutiva da lei natural, ele raciocina por um processo semelhante "àquele no qual nas ciências se produzem conclusões demonstrativas dos princípios"; isto é, por um processo semelhante a uma dedução (2003d, ST,I-II, q. 95 a.2c). Em contrapartida, quando o legislador está diante de múltiplas opções compatíveis com a lei natural, a ponto de pesar os custos e os benefícios, os riscos e as vantagens, ele desenvolve um trabalho intelectual criativo denominado por Aquino de determinatio (2003d, ST, I-II, q. 95 a.2c).
} 
Artigo: Bens básicos, moralidade e dignidade da pessoa humana: fundamentos da teoria da lei natural de Tomás de Aquino

flexível em diferentes momentos, ora quando enfatiza que a lei positiva não deve se ocupar dos menores vícios (AQUINO, 2003d), ora quando destaca que a disciplina legal deve ser imposta gradualmente (2003d), ora quando recomenda que as autoridades públicas admitam certos males graves (2003e). Suas lições sequer criam obstáculos ao fato notório de que os próprios absolutos morais, para serem positivados em prol da justiça e do bem comum, precisam passar por um trabalho legislativo que os complemente com especificações não substanciais atreladas ao ambiente histórico-cultural - tais quais: a estipulação de punição base em caso de violação, a determinação de autoridade competente para julgar o ilícito, a fixação de rito processual etc.

Se intolerante fosse, a lei natural tomista preconizaria um único caminho conciliável com a razão. Não é isso o que se verifica no trabalho de Aquino. Antes, este demonstra "senso muito agudo e compreensivo da vida humana e de suas contingências (ratio pratica est circa operabilia, quae sunt singulariza et contigentia), ensinando que mais de uma solução particular pode ser compatível, em certo tempo e lugar, com os imperativos da lei natural" (REALE, 2002, p. 611).

\section{DIGNIDADE DA PESSOA HUMANA}

Apreendido o conteúdo das linhas anteriores, resta, enfim, explicitar a sua relação com a dignidade humana pensada por Aquino.

Para ele, acredite-se ou não na existência divina, o homem é digno porque possui uma aptidão que apenas um ser especificamente semelhante a Deus, embora de maneira imperfeita, teria - qual seja: a aptidão de dominar a si mesmo; de determinar os próprios passos, esculpindo-se. E isso significa que o homem é pessoa, um todo uno racional (AQUINO, 2003a, 2003d).

Amparado pela personalidade, o ser humano pode assimilar o sentido dos objetos, pode ordenar os fatos existentes, pode alterar o estado bruto das coisas. O homem, e só o homem, sob a condição pessoal, tem a capacidade de modelar conscientemente a natureza à sua imagem, dando ao mundo um dinamismo criativo que nenhuma outra espécie conseguiria. Ele entende, explica e inova. Ele consiste em uma figura pronta e acabada que reserva infinitas possiblidades.

Não se questiona aqui o hábito que o ser humano possui de chamar ao mal pelo bem, e ao bem, mal, violando ou desacreditando muitos deveres e direitos morais, alguns imutáveis, 
alguns variáveis. Porém os seus equívocos intelectuais não suprimem, nem diminuem, o seu valor intrínseco. "A dignidade é um absoluto e pertence à essência”, diz Aquino (2003a, ST, I, q. 42 , a.4c).

O mesmo pode ser dito relativamente à objeção comum de que a dignidade da pessoa humana representa uma categoria histórica, uma conquista de origem social decorrente do processo de civilização (DURKHEIM, 2010). Ora, esse dado é autêntico, todavia levá-lo adiante para desqualificar a excelência natural do homem não passa de falácia lógica. $O$ fato de a dignidade da pessoa humana ter-se convertido em experiência social em determinado momento da história não elimina a verdade de que o valor máximo do homem já estava na sua natureza. O ser humano sempre esteve cingido por uma eminência própria, e o desvelar desse fato real no tempo é um retrato significativo do seu amadurecimento pessoal.

No centro do jusnaturalismo de Aquino, pois, nenhuma cegueira intelectual afasta do homem a inerência do seu valor absoluto. Não importam as contingências da vida, a dignidade da pessoa humana transcende as variações ou imutabilidades acidentais. Se o ser humano é originado com amor ou com luxúria, se o seu nascimento é seguido de alegria ou angústia, se em sua existência ele promove o bem ou o mal, se ele é rico ou pobre, novo ou velho, sadio ou doente, bonito ou feio, europeu ou americano, nada disso é relevante para reconhecê-lo em apreço irrestrito. Tão logo o ser humano surge para o mundo, ele vale; e vale integralmente até a morte.

Como bem alude o tomista Patrick Lee (2010, p. 54-55, tradução nossa),

[...] embora os seres humanos se diferenciem imensamente em relação a talentos, realizações, inteligência e até mesmo em relação à virtude moral, todos eles são iguais em ter a mesma natureza. Assim, dado que as pessoas humanas compartilham algum tipo de dignidade igualitária fundamental, essa dignidade fundamental deve ser baseada em sua igual natureza. Os seres humanos são valiosos como sujeitos de direitos em virtude do que são - e não em virtude de algum atributo acidental adquirido depois de virem a ser. Dessa forma não chegamos a ser em um momento e então adquirimos valor intrínseco como um sujeito de direitos em um momento posterior. Em vez disso, possuímos uma dignidade fundamental, igual e inerente a partir do momento em que viemos a ser.

Vê-se, por aí, que Aquino estabelece um vínculo imediato entre o valor intrínseco do ser humano e a lei natural. Esta é uma lei da razão (prática), e, consequentemente, está fundada na personalidade que dignifica qualquer ser. Em outras palavras, o homem, devido a sua dignidade - a dignidade de existir como pessoa - acha-se pronto para conhecer bens básicos, instanciá-los moralmente, e alcançar os deveres e os direitos que o tutelam em 
Artigo: Bens básicos, moralidade e dignidade da pessoa humana: fundamentos da teoria da lei natural de Tomás de Aquino

máxima estima. Não há grandes dúvidas nesse ponto do pensamento de Tomás de Aquino. Porque é digno, o homem pode encontrar e resguardar o que lhe reserva a própria dignidade: os preceitos da lei natural.

Ao contrário daquelas perspectivas que fazem da excelência humana algo transpessoal, a ponto de associá-la à sociedade ou à coletividade, o jusnaturalismo tomista admite a fundamentação ontológica da dignidade do homem e a sua declaração na pessoa, no indivíduo concreto, o qual, pela razão, tem competência para atualizar vários bens básicos. Ser pessoa é ser uma totalidade, um todo universal aberto a diversificados deveres e direitos morais, de sorte que o estudo da teoria da lei natural não é senão, em ampla medida, o estudo do significado único do homem. Quem examina a questão jusnaturalista examina aquilo que o ser humano deve ser em virtude do que é; e o ser humano é, originariamente, "o que há de mais perfeito em toda a natureza" (AQUINO, 2003a, ST, I, q. 29 a.3c).

Da dignidade humana, em resumo, procede a lei natural. Os preceitos primeiros, segundos e terceiros, sendo trabalhos cognitivos, exigem sujeitos eminentes em si - pessoas. Nelas consta a mensagem jurídico-moral que a racionalidade, pouco a pouco, efetiva; os dados que corroboram a transcendência humana ante os demais seres e coisas terrestres.

\section{CONCLUSÃO}

Esclarecida a concepção jusnaturalista de Aquino ou, mais precisamente, conforme se anuncia na introdução, 1. o que são bens básicos; 2. o que são princípios práticos básicos; 3 . qual o fundamento da moralidade; 4. como absolutos morais podem ser conhecidos; e 5. qual o vínculo entre todos esses pontos e a dignidade humana, parece possível afirmar que a lei natural tomista consiste em um conjunto de preceitos referentes à ação ou à omissão, cujo conhecimento depende da excelência pessoal do ser humano e lhe propicia a manifestação de condutas razoáveis.

A primeira ordem ou classe desse conjunto de preceitos abrange, além do princípio autoevidente formal de que o bem é para ser feito e tudo o que lhe for contrário é para ser evitado, princípios autoevidentes dotados de conteúdo pré-moral e princípios autoevidentes dotados de conteúdo moral; todos, em regra, assimilados durante a infância. Enquanto os princípios autoevidentes dotados de conteúdo pré-moral partem da formulação inerente ao princípio autoevidente formal (de que o bem é para ser feito e tudo o que lhe é contrário é para ser evitado), os princípios autoevidentes dotados de conteúdo moral vão adiante: eles, 
por conta do intercâmbio das experiências de amor e de entendimento dos bens básicos, estipulam genericamente aquilo que deve ser feito e aquilo que deve ser evitado. Parafraseando Aquino, a primeira ordem ou classe da lei natural comporta proposições indemonstráveis inscritas na razão humana, juízos per se nota omnibus, a exemplo do princípio formal da razão prática, dos princípios práticos básicos e do princípio supremo da moralidade.

Estão compreendidas, por outro lado, na segunda ordem ou classe de preceitos da lei natural tomista, certas normas morais específicas, as quais, em virtude da sua proximidade com os preceitos da primeira ordem ou classe, podem ser alcançadas por dedução mesmo pelas pessoas de inteligência ordinária. Entre tais normas, diz Aquino, encontram-se não só aqueles deveres e direitos sujeitos à exceção, mas também alguns deveres e direitos absolutamente necessários para a consecução da justiça e do bem comum, duas exigências de qualquer ordenamento jurídico-positivo.

Por fim, Aquino dispõe na terceira ordem ou classe da lei natural verdades práticas reservadas aos mais sábios. Somente as pessoas que levam uma vida razoável estão aptas a instanciar por si mesmas estes últimos preceitos, dos quais o nível de sofisticação intelectual demanda diversificadas considerações a respeito de diferentes circunstâncias.

É à luz dessa estrutura que o jusnaturalismo tomista destaca-se na história das ideias jurídicas. Enraizada na dignidade humana e desenvolvida a partir de considerações lógicas atreladas à razoabilidade prática, a teoria da lei natural proposta por Tomás de Aquino orienta o homem a ser o que moralmente ele deve ser, permitindo uma profunda assimilação do que é adequado à solução de inúmeros conflitos. Ou seja, ela ajuda o ser humano a sedimentar o conhecimento que ele já possui sobre os bens básicos, de modo a tornar viável a resolução, concreta e correta, dos problemas advindos da ignorância ou de descuidos morais.

Este é o grande mérito de Aquino ao tratar da questão jusnaturalista: alinhar a prática a aspectos teóricos sem se deixar dominar por esquemas formais distantes das crises que se operam na realidade. Em cada relação, em cada comunidade, em cada contexto histórico, o homem, pela lei natural, pode edificar a boa conduta, uma coexistência segundo benefícios inquestionáveis. 
Artigo: Bens básicos, moralidade e dignidade da pessoa humana: fundamentos da teoria da lei natural de Tomás de Aquino

\section{REFERÊNCIAS}

AQUINO, Tomás de. Suma teológica: v. 1. Tradução coordenada por Carlos-Josaphat Pinto de Oliveira. 2. ed. São Paulo: Loyola, 2003a.

AQUINO, Tomás de. Suma teológica: v. 2. Tradução coordenada por Carlos-Josaphat Pinto de Oliveira. 2. ed. São Paulo: Loyola, 2003b.

AQUINO, Tomás de. Suma teológica: v. 3. Tradução coordenada por Carlos-Josaphat Pinto de Oliveira. 2. ed. São Paulo: Loyola, 2003c.

AQUINO, Tomás de. Suma teológica: v. 4. Tradução coordenada por Carlos-Josaphat Pinto de Oliveira. 2. ed. São Paulo: Loyola, 2003d.

AQUINO, Tomás de. Suma teológica: v. 5. Tradução coordenada por Carlos-Josaphat Pinto de Oliveira. 2. ed. São Paulo: Loyola, 2003e.

AQUINO, Tomás de. Suma teológica: v. 6. Tradução coordenada por Carlos-Josaphat Pinto de Oliveira. 2. ed. São Paulo: Loyola, 2003f.

AQUINO, Tomás de. Suma teológica: v. 7. Tradução coordenada por Carlos-Josaphat Pinto de Oliveira. 2. ed. São Paulo: Loyola, 2003g.

AQUINO, Tomás de. Suma teológica: v. 9. Tradução coordenada por Carlos-Josaphat Pinto de Oliveira. 2. ed. São Paulo: Loyola, 2003h.

AQUINO, Tomás de. Summa theologica: v. 2. Tradução coordenada pelos Dominicanos. Nova York: Christian Classics, 1981.

DURKHEIM, Emile. Sociology and Philosophy. Tradução de D. F. Pocock. Nova York: Routledge, 2010.

FINNIS, John. Aquinas: moral, political and legal theory. Nova York: Oxford University Press, 1998.

FINNIS, John. Moral absolutes: tradition, revision and truth. Washington: The Catholic University of America Press, 1991.

FINNIS, John; BOYLE, Joseph; GRISEZ, Germain. Nuclear deterrence, morality and realism. New York: Oxford University Press, 1987.

FINNIS, John; GRISEZ, Germain; BOYLE, Joseph. Practical Principles, Moral Truth, and Ultimate Ends. American Journal of Jurisprudence 32, p. 99-151, 1987.

GEORGE, Robert. In defense of natural law. Nova York: Oxford University Press, 2001.

GEORGE, Robert. Natural law, God and human dignity. In: DUKE, George; GEORGE, Robert (ed.). The Cambridge Companion to Natural Law Jurisprudence. Cambridge: Cambridge University Press, 2017. 
GÓMEZ-LOBO, Alfonso. Morality and human goods: an introduction to natural law ethics. Washington: Georgetown University Press, 2002.

GRISEZ, Germain. The first principle of practical reason: a commentary on the Summa Theologiae, 1-2 Question 94, Article 2. Natural Law Forum, paper 107, p. 168-201, Jan. 1965.

LEE, Patrick. Abortion and unborn human life. 2nd. ed. Washington: Catholic University of America Press, 2010.

LEE, Patrick. Human nature and moral goodness. In: CHERRY, Mark J. (ed.). The normative of the natural: human goods, human virtue, human flourishing. Austin: Springer, 2009.

MARCEL, Gabriel. Homo viator: introduction to a metaphysic of hope. Tradução de Emma Craufurd. Chicago: Henry Regnery Company, 1951.

MAY, William E. Moral absolutes: catholic tradition, current trends and truth. Milwaukee: Marquette University Press, 1989.

RAWLS, John. A theory of justice. Cambridge: Harvard, 1971.

REALE, Miguel. Filosofia do direito. 20. ed. São Paulo: Saraiva, 2002.

RIBEIRO, Mário da Silva. Aborto: fundamentos biológico-filosóficos da sua (anti)juridicidade. 2019. 175 f. Dissertação (Mestrado em Direito) - Programa de PósGraduação em Direito da Universidade Federal do Pará (PPGD - UFPA), 2019.

TOLLEFSEN, Christopher. Natural law, basic goods and practical reason. In: DUKE, George; GEORGE, Robert (ed.). The Cambridge Companion to Natural Law Jurisprudence. Cambridge: Cambridge University Press, 2017. 